Purdue University Purdue e-Pubs

LARS Symposia

Laboratory for Applications of Remote Sensing

$1-1-1979$

\title{
Threshold Selection for Line Detection Algorithms
}

Charlotte M. Gurney

Follow this and additional works at: http://docs.lib.purdue.edu/lars_symp

Gurney, Charlotte M., "Threshold Selection for Line Detection Algorithms" (1979). LARS Symposia. Paper 293.

http://docs.lib.purdue.edu/lars_symp/293

This document has been made available through Purdue e-Pubs, a service of the Purdue University Libraries. Please contact epubs@purdue.edu for additional information. 
Reprinted from

Symposium on

\title{
Machine Processing of Remotely Sensed Data
}

\author{
June 27 - 29, 1979 \\ The Laboratory for Applications of \\ Remote Sensing \\ Purdue University \\ West Lafayette \\ Indiana 47907 USA \\ IEEE Catalog No. \\ 79CH1430-8 MPRSD \\ Copyright (C) 1979 IEEE
}

The Institute of Electrical and Electronics Engineers, Inc.

Copyright (C) 2004 IEEE. This material is provided with permission of the IEEE. Such permission of the IEEE does not in any way imply IEEE endorsement of any of the products or services of the Purdue Research Foundation/University. Internal or personal use of this material is permitted. However, permission to reprint/republish this material for advertising or promotional purposes or for creating new collective works for resale or redistribution must be obtained from the IEEE by writing to pubs-permissions@iee.org.

By choosing to view this document, you agree to all provisions of the copyright laws protecting it. 
THRESHOLD SELECTION FOR LINE DETECTION ALGORITHMS

CHARLOTTE M. GURNEY

Department of Geography, University of Reading and Image Analysis Group, A.E.R.E. Harwell, U.K.

A line detector has been derived which combines the advantages of existing 'non-linear' and 'semi-linear' methods. It has been tested on Landsat data of S.E. England where linear features are typically less than one pixel in width. Improved results have been obtained in comparison with alternative methods.

Specification of an accurate threshold value is essential for deciding whether a pixel contains a linear feature or not. This may be achieved using a model which attempts to determine the threshold value from the following properties:

1. The width of the linear feature

2. The spectral response of the linear feature

3. The spectral response of the background cover type

4. The configuration of the line with respect to the pixel boundaries

5. Pixel overlap

6. Spatial autocorrelation in the pixel window used by the linear feature detector.

Results show that at any one threshold, sections of very narrow lines may be detected while sections of much wider lines may be missed. Typically, in the area studied, rivers as narrow as $10 \mathrm{~m}$ wide may be detected under optimum conditions whereas, using the same threshold, sections of rivers as wide as $60 \mathrm{~m}$ were not detected. Noise will therefore be introduced into any detection process. However, it is shown that this noise may be reduced by post-processing and examples are given which demonstrate that this is most effective when information is combined from line detectors applied at different thresholds. 